\title{
From the Publisher
}

\author{
Mary Jo Callan \\ Director, Edward Ginsberg Center \\ University of Michigan
}

This issue marks a transition as Jeff Howard retires after 23 years as founding Editor of the Michigan Journal of Community Service Learning (MJCSL). We applaud the distinguished service and leadership that Jeff has provided since our first issue in 1994, and are gratified to have seen the MJCSL's impact grow in both national and international contexts. During Jeff's tenure, the MJCSL has published hundreds of contributions demonstrating the power of service-learning and community engagement. The MJCSL has nurtured several generations of service-learning educators, campus-community partnership practitioners, and community-engaged scholars. It has served as a key resource, an outlet for sharing research, and an opportunity for professional service for many of the foremost scholars and powerful voices in the field. We will miss Jeff's leadership, and we wish him well.

The Edward Ginsberg Center at the University of Michigan is proud to publish the MJCSL, which informs and enhances our work to provide a crucible for transformational learning, service, and community impact. Now more than ever, service-learning and community engagement centers are important institutional assets, where we nurture scholars, but more importantly, where we help to develop the leaders and citizens that our increasingly complex and challenged world needs. This work is at the intersections: of higher education and communities, of student identities and experiences, of disciplines and perspectives, of Academic and Student Affairs, of faculty and staff. It is at these intersections where the most powerful outcomes and impacts are created for students and for the public good.
As the publisher of the MJCSL, we see part of our current responsibility as doubling down on that public good. Now is the time to lead higher education in demonstrating our relevance - our centrality to building and sustaining healthy communities - and the importance of service-learning and community engagement being centered on that community impact and benefit.

As the work of the service-learning and community engagement field continues to develop and grow, so must we expand on the strong foundation created by the MJCSL. We are committed to remaining a leading source of scholarship on servicelearning and community engagement, maintaining its rigor and reliability. However, since communityengaged scholarship and practices have evolved over the last twenty years, we seek to ensure that the MJCSL is fully reflective of our role as leaders in public scholarship and a resource and outlet for scholars, practitioners, and our community partners. In these pages, we have observed and commented on the difficulty of measuring outcomes and impacts of our work with community partners, as well as the long-term impacts of our work with students. Where we are still asking questions, we need to ensure that we are answering them.

I invite you to join us in reimagining an outlet for public scholarship rooted in, and more fully reflective of, the interests of community. We look forward to continuing to ensure that service-learning, and community-engaged scholarship more broadly, lives up to its promise - for students, for community partners and communities, for our democracy, and for our world. 